\title{
Molecular diversity of Extended-spectrum $\beta$-lactamase-producing Escherichia coli from vultures in Canary Islands
}

Isabel Carvalho, (1),2,3,4,5 María Teresa Tejedor-Junco, ${ }^{6,7}$ Margarita González-Martín, ${ }^{6,7}$ Juan Alberto Corbera ${ }^{6,8}$ Alejandro Suárez-Pérez, ${ }^{8}$ Vanessa Silva, ${ }^{1,2,3,4}$ Gilberto Igrejas, ${ }^{2,3,4}$ Carmen Torres $\mathbb{1}^{5}$ and Patrícia Poeta (10) ${ }^{1,4 *}$

${ }^{1}$ Microbiology and Antibiotic Resistance Team (MicroART), Department of Veterinary Sciences, University of Trás-os-Montes and Alto Douro, Vila Real, Portugal.

${ }^{2}$ Department of Genetics and Biotechnology, University of Trás-os-Montes and Alto Douro, Vila Real, Portugal. ${ }^{3}$ Functional Genomics and Proteomics Unit, University of Trás-os-Montes and Alto Douro, Vila Real, Portugal.

${ }^{4}$ Laboratory Associated for Green Chemistry (LAQVREQUIMTE), New University of Lisbon, Monte da Caparica, Portugal.

${ }^{5}$ Area Biochemistry and Molecular Biology, University of La Rioja, Logroño, Spain.

${ }^{6}$ Research Institute of Biomedical and Health Sciences, University of Las Palmas de Gran Canaria, Canary Islands, Spain.

${ }^{7}$ Department of Clinical Sciences, University of Las Palmas de Gran Canaria, Canary Islands, Spain. ${ }^{8}$ Department of Animal Pathology, Veterinary School, University of Las Palmas de Gran Canaria, Canary Islands, Spain.

\section{Abstract}

Antimicrobial resistance among isolates from wild animals is increasingly reported. Extended-spectrum beta-lactamase (ESBL)-producing Enterobacteriaceae, and particularly Escherichia coli, have spread worldwide as one of the most common multidrug-resistant organisms. The aim of this study was to determine the carriage rate of ESBL-producing $E$. coli isolates and

Received 8 June, 2020; accepted 1 August, 2020. *For correspondence. E-mail ppoeta@utad.pt; Tel. (+351)-259350466; Fax (+351)259350629. Preliminary results were presented as an abstract and poster presentation at the 30th ECCMID 2020, April, Paris, France. their genetic characteristics in wild vultures from the Canary Islands. Faecal samples were collected from 22 apparently healthy free-ranging (wild) vulture chicks from Lanzarote and Fuerteventura (Canary Islands) during July 2019. They were seeded in MacConkey agar supplemented with cefotaxime $\left(2 \mu \mathrm{g} \mathrm{ml}^{-1}\right)$. Colonies with typical morphology of $E$. coli were identified by MALDI-TOF-MS. Antimicrobial susceptibility was done by disk diffusion. Phenotypic detection of ESBL was performed by double-disk tests. The presence of bla $_{\mathrm{CTX}-\mathrm{M}}, b / a_{\mathrm{SHV}}, b a_{\mathrm{TEM}}, b / a_{\mathrm{KPC}}$ and $b / a_{\mathrm{OXA}-48}$ genes, as well as mcr-1 (colistin resistance), tetA/tetB and int1 gene, was tested by PCR/sequencing. Phylogenetic groups and multilocus sequence typing (MLST) were determined by PCR/sequencing. ESBL-producing $E$. coli isolates were detected in $5 / 22$ tested animals (22.7\%), and all isolates (one/animal) carried bla genes: $b_{\text {la }}$ CTX-M-15 $(n=3)$ and bla positive isolates were ascribed to phylogenetic group $D$ (two isolates), $B_{1}$ (two isolates) and A (one isolate), and five sequence types were detected (ST/phylogeneticgroup/ESBL): ST515/B1/CTX-M-15, ST1290/A/CTX-M-15, ST38/D/CTX-M-15, ST457/D/CTX-M-55 and ST6448/B 1 CTX-M-55; this suggests a genetic diversity among these isolates. Three CTX-M-15-producing isolates contained the $b / a_{\mathrm{TEM}}$ gene and one the tetA gene. To our knowledge, this appears to be the first report of ESBLproducing $E$. coli in vulture chicks from the Canary Islands.

Introduction

Antibiotics are one of the biomedical revolutions of the 20th century. However, antibiotic resistance constitutes a public health problem nowadays. The excessive use of antibiotics is directly related to the great spread of antibiotic resistance (Pinto et al., 2010; Carvalho et al., 2019; Ma et al., 2017). The abuse and misuse of these drugs can also compromise the prevention and treatment of an increasing range of bacterial infections (WHO, 2017). Therefore, antimicrobial resistance is a 'One Health' 
issue (Robinson et al., 2016). 'One Health' is an emerging concept that establish that human, animal and environmental health are interconnected, and a global strategy is needed to face this challenge (Lee et al., 2018).

Regarding this situation, different studies have been done in order to understand the mechanisms of bacterial drug resistance in pets and humans (Puño-Sarmiento et al., 2013; Leite-Martins et al., 2014; Marinho et al., 2016; Chung et al., 2017; Derakhshandeh et al., 2018; Sato et al., 2018). Wild birds are also potential reservoirs of resistant bacteria and have the potential to transmit antibiotic resistance, including clinically important resistance genes. During the last two decades, different studies have been published in Europe regarding antimicrobial resistance among wild animals (Costa et al., 2008; Poeta et al., 2008; Radhouani et al., 2012; Gonçalves et al., 2014; Dias et al., 2015; Alcala et al., 2016; Wang et al., 2017). Wildlife are not directly exposed to clinically useful antimicrobial agents, but they can acquire resistant bacteria mainly through water polluted from faeces of human and farm activity (Mora et al., 2014).

Extended-spectrum $\beta$-lactamase (ESBL)-producing Enterobacteriaceae, and particularly Escherichia coli, have spread worldwide as one of the most common multidrug-resistant organisms. Two of the most clinically relevant antimicrobial resistance mechanisms are the production of ESBLs and plasmid-mediated AmpC-type $\beta$-lactamases (pAmpC). Escherichia coli is a commensal bacterium, which inhabits in the gastrointestinal tract of warm-blooded animals, and can also be a reservoir for antibiotic resistance (Iredell et al., 2016; Ulstad et al., 2016; Marques et al., 2018). The genes encoding these enzymes are frequently plasmid-located and can be horizontally transferred to other bacteria (Alcala et al., 2016; Alonso et al., 2017). The spread of $E$. coli strains producing CTX-M-type $\beta$-lactamases is mostly responsible for the increased incidence of ESBL, especially CTX-M-15 variant, both in animals and humans (Belas et al., 2014; Ewers et al., 2014; Kojima et al., 2014; Rocha-Gracia et al., 2015; Zorgani et al., 2017).

The Iberian Peninsula holds $>90 \%$ of the European population of wild vultures (Lopez-Cerero et al., 2017). The Egyptian vultures (Neophron percnopterus) are the smallest and least dominant of the European vultures (Moreno-Opo et al., 2020). Until a few decades ago, the wild Canarian Egyptian vulture (Neophron percnopterus var. majorensis), a subspecies of Egyptian vulture, with a small population inhabited practically in all Canary Islands (Spain), although currently it is only preserved in specific areas of Lanzarote and Fuerteventura Islands. The vultures' population in the Canary Islands has increased by $12 \%$ during 2018 (311 individuals recorded in 2017 to 349 individuals) thanks to protection programs promoted by the Regional Government Ministry of Territorial Policy, Sustainability and Security within the European Program Life Egyptian Vulture 2019 (Life Egyptian Vulture (LEV), 2019). According to these same authors, the vultures' population included 361 animals at the end of 2019 (with an increase of 12 vultures, corresponded to $3.4 \%$ ), from which 163 were classified as reproductive and 198 as non-reproductive animals.

To our knowledge, this is the first report related to ESBL-producing E. coli done in Canarian Egyptian vultures. Even though antibiotic resistance in vultures has been less studied than in other domestic animals worldwide (Ahmed et al., 2010; Tuerena et al., 2016; Carvalho et al., 2017; Saputra et al., 2017; Rumi et al., 2019; Suay-Garcia et al., 2019), there are some recent available data in different Spanish cities that suggest that Neophron percnopterus might have an important role in the spread of ESBL/pAmpC bacteria (Alcala et al., 2016; Lopez-Cerero et al., 2017; Moreno-Opo et al., 2020; Sevilla et al., 2020). In this way, contact with urban waste and livestock farming has been associated with increased probability of antibiotic-resistant microbiota in wild birds, especially ESBL-producing $E$. coli. The aim of this study was to determine the carriage rate of ESBLproducing $E$. coli as well as their genetic characteristics in samples obtained from Canarian Egyptian vultures (Neophron percnopterus var. majorensis) from Fuerteventura and Lanzarote (Canary Islands), in Spain. Furthermore, One Health aspects of antimicrobial resistance will be investigated.

\section{Results and discussion}

Five of the 22 faecal samples tested carried cefotaximeresistant $\left(C T X^{R}\right)$ E. coli isolates, and were ESBL-producers, representing $22.7 \%$ of total samples tested. A similar prevalence of ESBL-producing $E$. coli was found in studies done with black vultures from Mongolia (27\%) (Guenther et al., 2013) and from three different vulture' species in central Spain (26\%) (Lopez-Cerero et al., 2017). In the same line, Pinto et al. (2010) found a similar prevalence of ESBL-positive isolates among wild birds of prey at the Serra da Estrela Natural Reserve in Portugal (26.9\%). In contrast, Mora et al. (2014) did not found any ESBL-producing $E$. coli between griffon vultures from Southeast of Spain.

Four of our ESBL-producing E. coli isolates were obtained from Fuerteventura and only one from Lanzarote Island (Table 1). All of them exhibited a multidrugresistant phenotype (Table 1), which is in accordance with the results obtained with Egyptian vultures in other regions of the Spanish peninsula (Lopez-Cerero et al., 2017). It is interesting to note that the ESBL-producing 
Table 1. Phenotype and genotype of antimicrobial resistance of the five ESBL-producer E. coli isolates recovered from vultures in the Canary Islands.

\begin{tabular}{|c|c|c|c|c|c|c|}
\hline Isolate number & Origin $^{a}$ & Antimicrobial resistance phenotype ${ }^{b}$ & $\beta$-lactamase genes & Other genes & $P G^{c}$ & MLST \\
\hline $\mathrm{X} 1888$ & FV & AMP, CTX, TET, CN & CTX-M-15, TEM & & B1 & ST515 \\
\hline X1889 & FV & AMP, AMC, FOX, CTX, CAZ, TET, SXT, CHF, CIP & CTX-M-15, TEM & int 1 & A & ST1290 \\
\hline X1890 & $\mathrm{LZ}$ & AMP, CTX, CAZ, SXT, TET & CTX-M-15, TEM-1 & tetA, int 1 & $\mathrm{D}$ & ST38 \\
\hline X1891 & FV & AMP, CTX, CAZ, SXT, TET, CHF, CIP & CTX-M-55 & int 1 & B1 & ST6448 \\
\hline X1927 & FV & AMP, CTX, CAZ & CTX-M-55 & & $\mathrm{D}$ & ST457 \\
\hline
\end{tabular}

${ }^{\mathrm{a}} \mathrm{FV}$ : Fuerteventura; LZ: Lanzarote.

bAMP: ampicillin; AMC: amoxicillin + clavulanic acid; FOX: cefoxitin; CTX: cefotaxime; CAZ: ceftazidime; TET: tetracycline; SXT: trimethoprimsulphamethoxazole; CN: gentamicin; S: streptomycin; ERT: ertapenem; CHF: chloramphenicol; CIP: ciprofloxacin.

'PG: Phylogenetic group.

isolates found in this study might have an impact on public health if transmitted to humans (Bessalah et al., 2016; Grzywaczewski et al., 2016). Recently, Sharma et al. (2018) found a high rate of beta-lactam resistance among E. coli strains in migrant Egyptian vultures in Iran. None of our isolates showed resistance to imipenem (Table 1).

Although the migratory behaviour of raptors has been proposed as a mechanism for the dissemination of antimicrobial-resistant genes (Wang et al., 2017), our study is focused on Canarian Egyptian vulture that is not migratory and inhabits only in two islands (Fuerteventura and Lanzarote) of Canary Islands Archipelago. Therefore, only the feeding habits linked to the consumption of remains from intensive livestock farming, especially pigs (Blanco et al., 2019) as well as on garbage that accumulate in rubbish dumps (Tauler-Ametler et al., 2018) has been associated with a higher probability of antibioticresistant microbiota in wild vultures, especially ESBLproducing $E$. coli.

All our isolates carried bla bla $a_{\mathrm{CTX}-\mathrm{M}-15}$ (three isolates) and b/a $\mathrm{a}_{\mathrm{CTX}-\mathrm{M}-55}$ (two isolates), illustrated in Table 1. All CTX-M-15-producing isolates contained the bla $\mathrm{TEM}_{\mathrm{TEM}}$ gene and one carried the tet (A) gene. Furthermore, three isolates contained the int1 gene (Table 1). Pinto et al. (2010) detected a high prevalence of CTX-M-1 in ESBL-positive faecal $E$. coli isolates recovered from birds of prey $(87.5 \% ; n=28 / 32)$ at the Serra da Estrela Natural Reserve (Portugal); this ESBL type (CTX-M-1) was also previously reported in studies done by our research group in healthy pets (Costa et al., 2004) and wild animals (Costa et al., 2006; Poeta et al., 2008). Furthermore, Costa et al. (2006) detected ESBL producers in $35.7 \%$ of the birds of prey studied (5/14 animals), namely CTX-M-1, CTX-M-14 and SHV-12. In Spain, Alcala et al. (2016) observed the presence of bla $\mathrm{CTX}_{\mathrm{C}-\mathrm{M}-1}$ gene in a griffon vulture and Lopez-Cerero et al. (2017) found the same gene among Egyptian vultures (Neophron percnopterus) samples. Other types of beta-lactamases were detected by Batalha-de-Jesus et al. (2019) among vultures' samples from Brazil: CTXM-2, CTX-M-15 and CTX-M-8. Regarding the black vultures isolates from Mongolia, the CTX-M-9 was the most prevalent ESBL detected (Guenther et al., 2013).

None of our $E$. coli isolates carried the bla $\mathrm{SHV}_{\mathrm{H} V}$ or bla OXA-48 genes. The mcr-1 determinant, encoding colistin resistance, was studied in all $E$. coli isolates of this work, and all of them were mcr-1 negative. However, Oteo et al. (2018) found this gene in one black vulture in Spain. In addition, the focus on chicks might have decreased the frequency of antimicrobial-resistance genes found in their microbiome since such immature birds would be less likely than adult birds to full exposure to environmental antimicrobial resistance genes.

High genetic diversity was observed among the five ESBL $E$. coli isolates with five different sequence types (STs) and three different phylogenetic groups (ST/phylogenetic-group/ ESBL): ST515/B /CTX-M-15, ST1290/A/CTX-M-15, ST38/D/ CTX-M-15, ST457/D/CTX-M-55 and ST6448/B /CTX-M-55; this suggests a genetic diversity among these isolates including several strains of STs frequently detected among human clinical isolates. Nevertheless, the lineage ST131 widely disseminated in humans was not detected in this study. These results are in line with another Spanish previous study performed in $E$. coli from healthy dogs showing the detection of ST38 and ST457 (Flament-Simon et al., 2019). It is important to note that ST457 E. coli is a recent clone with the capacity to cause antimicrobial-resistant extraintestinal infection, almost certainly in dogs, wild animals and possibly in humans (Nicolas-Chanoine et al., 2014). Agreeing with our results, a study done by Batalha-de-Jesus et al. (2019) showed the presence of CTX-M-2/ST457 in wild birds from Brazil. The ST38 is considered a globally dispersed high-risk clone of extraintestinal pathogenic E. coli commonly associated with urinary tract infections and bacteremia in humans (Hernandez et al., 2013; Dolejska and Literak, 2019; Shnaiderman-Torban et al., 2020) but also found in wildlife (Alcala et al., 2016; Guenther et al., 2017). According to a recent study, the ST38/ CTX-M-15-resistant clone was found in a Mongolian wild 
bird (Guenther et al., 2017) and the same combination was detected in a human clinical isolate in India (Guiral et al., 2019). These results are in line with the fact that ST38 lineage is considered an expanded and pandemic clone as well as this lineage appears to be independent of antimicrobial selective pressure in clinical environments (Guenther et al., 2017). The ST515 lineage, also found in our study, has been previously found by Dandachi et al. (2018) in poultry from Lebanon, harbouring the mcr-1 gene. The same variant was identified in an E. coli clinical isolate obtained from a patient in a Canadian hospital (Walkty et al., 2016).

Few reports have been done concerning the prevalence and characterization of ESBL-producer $E$. coli in the faecal microbiota of healthy vultures, and most of the studies have focused on $E$. coli isolates from domestic animals (Stolle et al., 2013; Ewers et al., 2014; Marques et al., 2016; Pulss et al., 2018) or in wild birds or vultures only from Spanish peninsula (Alcala et al., 2016; Lopez-Cerero et al., 2017; Moreno-Opo et al., 2020). To our knowledge, this is the first study on the genetic background in commensal $E$. coli isolates recovered from Canarian Egyptian vultures in the Canary Islands.

However, we cannot exclude the possibility that these wild animals had been exposed to faecal material of farm animals or even that of humans. These facts might be involved in the acquisition and dissemination of antibiotic-resistant bacteria even in the absence of direct antibiotic pressure and might explain the presence of ESBL-producing E. coli isolates. The results of our study support the idea that raptors can act as carriers and spreaders of ESBL-producing E. coli representing a risk not only for wildlife but also for livestock and the human population. It is important to note the risk of ESBL-producing E. coli for the professionals that work with wild animals, including vultures (Grzywaczewski et al., 2016).

\section{Experimental procedures}

\section{Animals and sampling}

A total of 22 faecal samples from apparently healthy chicks of wild Canarian Egyptian vultures (Neophron percnopterus var. majorensis) from Lanzarote $(n=1)$ and Fuerteventura $(n=21)$ were obtained during July 2019 (Fig. 1). All the faecal samples were collected individually using a sterile cotton swab from each animal and were obtained in collaboration with researchers of a long-term monitoring program of vulture population and were processed at the Research Institute of Biomedical and Health Sciences (University of Las Palmas de Gran Canaria, Spain). None of the animals had been fed previously by humans or had received antibiotics. The Neophron percnopterus var. majorensis is only distributed in Canary Island territory and it is not a migratory species.

Chicks were captured during the fledgling stage in nests. All procedures, including the capture and handling methods of wild vultures, were carried out under Project Licence approved by Dirección de Biodiversidad del Gobierno de Canarias (Canary Islands Government); competent authority official reference numbers 2014/256, 2015/1652 and 2016/1707.

\section{Escherichia coli isolation}

The faecal samples were inoculated onto MacConkey agar plates supplemented with $2 \mu \mathrm{g} \mathrm{ml}^{-1}$ of cefotaxime $(\mathrm{MC}+\mathrm{CTX})$ for cefotaxime resistant $\left(\mathrm{CTX} \mathrm{R}^{\mathrm{R}}\right) \mathrm{E}$. coli recovery. After incubation at $37^{\circ} \mathrm{C}$ for $24 \mathrm{~h}$, colonies showing E. coli morphology were recovered and identified by classical biochemical methods named IMViC (Indol, Methylred, Voges-Proskauer and Citrate) and Analytical Profile Index (API 20Egallery). The identification was confirmed with the matrix-assisted laser desorption/ionization timeof-flight mass spectrometry method (MALDI-TOF MS, Bruker) in the Laboratory of Biochemistry and Molecular

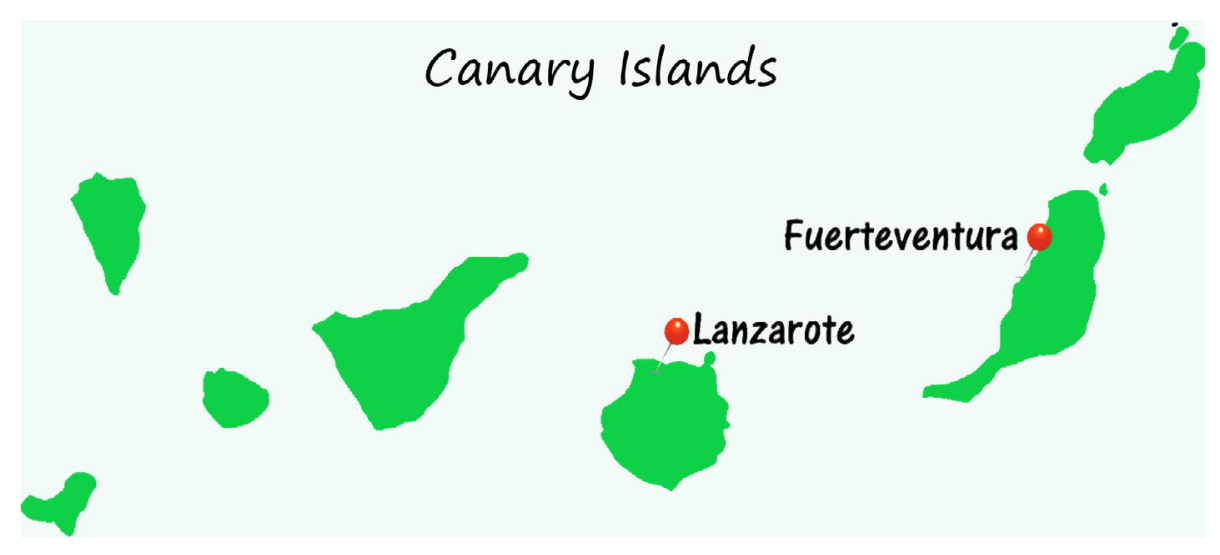

Fig. 1. Origin of vultures' samples: Fuerteventura and Lanzarote (Canary Islands, Spain). 
Biology in the University of La Rioja (Logroño, Spain). One E. coli per sample was kept and characterized by genetic methods.

\section{Susceptibility testing}

Antimicrobial susceptibility testing was performed by the agar disk diffusion method, as recommended by the Clinical Laboratory Standards Institute standard guidelines (CLSI, 2018). Escherichia coli isolates were tested against the following antimicrobial agents ( $\mu \mathrm{g} /$ disk): ampicillin (10), amoxicillin + clavulanic acid $(20+10)$, cefotaxime (30), cefoxitin (30), ceftazidime (30), aztreonam (30), imipenem (10), tetracycline (30), nalidixic acid (30), ciprofloxacin (5), trimethoprim-sulfamethoxazole $(1.25+23.75)$, gentamicin (10), tobramycin (10), streptomycin (10), amikacin (30) and chloramphenicol (30). Isolates were recorded as susceptible, intermediate, or resistant according to the interpretative standards of zone diameter (CLSI, 2018). The detection of ESBL production was carried out using three disks of antibiotics in the same line: cefotaxime, ceftazidime and amoxicillin/clavulanic acid (CLSI, 2018).

\section{DNA extraction and quantification}

Genomic DNA from ESBL-producing isolates was extracted using the InstaGene Matrix (BioRad), according to the manufacturer's instructions. In order to quantify the DNA concentration and the level of purity, the absorbance readings were taken at 260 and $280 \mathrm{~nm}$ (Spectrophotometer ND-100, Nanodrop).

\section{Antibiotic resistance genes}

The genetic basis of resistance was investigated using PCR and sequencing of the obtained amplicons. Positive controls of the University of La Rioja (Logroño, Spain) were used in this study.

The presence of the beta-lactamase genes [b/a $a_{\text {CTX-M }}$ (groups 1 and 9), bla ${ }_{\mathrm{SHV}}, b / a_{\mathrm{TEM}}, b / a_{\mathrm{OXA}-1}$, and bla $a_{\mathrm{OXA}-48}$ ] was studied by PCR and sequencing (Ruiz et al., 2012; Hassen et al., 2019). Furthermore, the mcr-1 (colistin resistance), tetA/tetB (tetracycline resistance) and int1 genes (integrase of class 1 integrons) were also analysed (Hassen et al., 2019). Virulence factors were also tested (sxt $\left.t_{1,2}\right)$ (Alonso et al., 2017).

The E. coli isolates were assigned according to the phylogenetic classification into one of the four main phylogenetic groups, $A, B_{1}, B_{2}$ and $D$, following a PCR strategy published previously based on the presence or absence of the chuA and yjaA gene or the DNA fragment TSPE4.C2 (Clermont et al., 2000).

\section{Multilocus sequence typing of $\mathrm{E}$. coli strains}

The MLST with seven housekeeping genes (icd, fumC, $m d h$, adk, recA, purA and gyrB) was carried out in the five ESBL-positive isolates, according to the PubMLST protocol for E. coli (PubMLST, 2020). The allele combination was determined after sequencing the seven genes, and the ST and clonal complex were identified.

\section{Conclusions}

Wild birds can contribute to the global spread of ESBLproducing $E$. coli in natural ecosystems. This study shows, for the first time in the Canary Islands, that vultures can be carriers of ESBL-producing E. coli isolates associated with diverse STs (ST515, ST1290, ST38, ST457 and ST6448). Our study reports the dissemination of bla $a_{\mathrm{CTX}-\mathrm{M}-15}$ and b/a $\mathrm{C}_{\mathrm{CTX}-\mathrm{M}-55}$ genes in $E$. coli isolates from vultures in the Canary Islands. This study supports the hypothesis regarding the circulation of antimicrobialresistance genes and antimicrobial-resistant bacteria between animals (in this case vultures), humans and the environment.

However, more studies focusing on the human-animal-environmental interface should be performed to better understand the role of these animals in the spread of this type of resistance and to assess potential risks for the public health from the 'One Health' approach.

\section{Acknowledgements}

We would like to thank José Antonio Donázar, Julio Roldán, Marina García-Alfonso, Thijs van Overveld and Manuel de la Riva for their help with sampling for this work.

\section{References}

Ahmed, M.O., Clegg, P.D., Williams, N.J., Baptiste, K.E., and Bennett, M. (2010) Antimicrobial resistance in equine faecal Escherichia coli isolates from North West England. Ann Clin Microbiol Antimicrob 9: 12.

Alcala, L., Alonso, C.A., Simon, C., Gonzalez-Esteban, C., Oros, J., Rezusta, A., et al. (2016) Wild birds, frequent carriers of extended-spectrum $\beta$-lactamase (ESBL) producing Escherichia coli of CTX-M and SHV-12 types. Microb Ecol 72: 861-869.

Alonso, C.A., Mora, A., Diaz, D., Blanco, M., GonzalezBarrio, D., Ruiz-Fons, F., et al. (2017) Occurrence and characterization of stx and/or eae-positive Escherichia coli isolated from wildlife, including a typical EPEC strain from a wild boar. Vet Microbiol 207: 69-73.

Batalha-de-Jesus, A., Souza, J., Martins, N., Botelho, L., Girão, V., Teixeira, L., et al. (2019) High-level multidrugresistant Escherichia coli isolates from wild birds in a large urban environment. Microb Drug Resist 25: 167-172.

Belas, A., Salazar, A.S., Gama, L.T., Couto, N., and Pomba, C. (2014) Risk factors for faecal colonisation with 
Escherichia coli producing extended-spectrum and plasmid-mediated ampC $\beta$-lactamases in dogs. Vet Rec 175: 202.

Bessalah, S., Fairbrother, J.M., Salhi, I., Vanier, G., Khorchani, T., Seddik, M.M., and Hammadi, M. (2016) Antimicrobial resistance and molecular characterization of virulence genes, phylogenetic groups of Escherichia coli isolated from diarrheic and healthy camel-calves in Tunisia. Comp Immunol Microbiol Infect Dis 49: 1-7.

Blanco, G., Cortés-Avizanda, A., Frías, Ó., Arrondo, E., and Donázar, J.A. (2019) Livestock farming practices modulate vulture diet-disease interactions. Glob Ecol Conserv 17: e00518.

Carvalho, I., Del Campo, R., Sousa, M., et al. (2017) Antimicrobial resistant Escherichia coli and Enterococcus spp. isolated from Miranda Donkey (Equus asinus): an old problem from a new source with a different approach. J Med Microbiol 66: 191-202.

Carvalho, I., Silva, N., Carrola, J., Silva, V., Currie, C., Igrejas, G., and Poeta, P. (2019) Chapter 11: Antibiotic resistance. In Antibiotic Drug Resistance. Hoboken: John Wiley \& Sons, pp. 239-259.

Chung, Y.S., Hu, Y.S., Shin, S., Lim, S.K., Yang, S.J., Park, Y.H., and Park, K.T. (2017) Mechanisms of quinolone resistance in Escherichia coli isolated from companion animals, pet-owners, and non-pet-owners. J Vet Sci 18: $449-456$.

Clermont, O., Bonacorsi, S., and Bingen, E. (2000) Rapid and simple determination of the Escherichia coli Phylogenetic Group. Appl Environ Microbiol 66: 4555-4558.

CLSI. (2018) Clinical and Laboratory Standards Institute. Performed Standards for Antimicrobial Susceptibility Testing, 28th ed. Wayne, PA: CLSI supplement.

Costa, D., Poeta, P., Briñas, L., Sáenz, Y., Rodrigues, J., and Torres, C. (2004) Detection of CTX-M-1 and TEM-52 $\beta$-lactamases in Escherichia coli strains from healthy pets in Portugal. J Antimicrob Chemother 54: 960-961.

Costa, D., Poeta, P., Saenz, Y., Vinue, L., Coelho, A.C., Matos, M., et al. (2008) Mechanisms of antibiotic resistance in Escherichia coli isolates recovered from wild animals. Microb Drug Resist (Larchmont, NY) 14: 71-77.

Costa, D., Poeta, P., Saenz, Y., Vinue, L., Rojo-Bezares, B., Jouini, A., et al. (2006) Detection of Escherichia coli harbouring extended-spectrum beta-lactamases of the CTX-M, TEM and SHV classes in faecal samples of wild animals in Portugal. $J$ Antimicrob Chemother 58: 1311-1312.

Dandachi, I., Chabou, S., Daoud, Z., and Rolain, J.M. (2018) Prevalence and emergence of extended-spectrum cephalosporin-, carbapenem- and colistin-resistant Gram negative bacteria of animal origin in the Mediterranean Basin. Front Microbiol 9: 2299.

Derakhshandeh, A., Eraghi, V., Boroojeni, A.M., Niaki, M.A., Zare, S., and Naziri, Z. (2018) Virulence factors, antibiotic resistance genes and genetic relatedness of commensal Escherichia coli isolates from dogs and their owners. Microb Pathog 116: 241-245.

Dias, D., Torres, R.T., Kronvall, G., Fonseca, C., Mendo, S., and Caetano, T. (2015) Assessment of antibiotic resistance of Escherichia coli isolates and screening of
Salmonella spp. in wild ungulates from Portugal. Res Microbiol 166: 584-593.

Dolejska, M., and Literak, I. (2019) Wildlife is overlooked in the epidemiology of medically important antibiotic-resistant bacteria. Antimicrob Agents Chemother 63: e0116701119.

Ewers, C., Bethe, A., Stamm, I., Grobbel, M., Kopp, P.A., Guerra, B., et al. (2014) CTX-M-15-D-ST648 Escherichia coli from companion animals and horses: another pandemic clone combining multiresistance and extraintestinal virulence? J Antimicrob Chemother 69: 1224-1230.

Flament-Simon, V.M., Alonso, P., García-Meniño, I., TrigoTasende, N., Blanco, J., Blanco, M., and Blanco, J. (2019) Prevalence and molecular characterisation of extraintestinal pathogenic Escherichia coli and ESBL/pAmpCproducing $E$. coli in healthy dogs in Spain, 29th ECCMID13-16 April 2019, Amsterdam, Netherlands, p. P1204.

Gonçalves, A., Poeta, P., Monteiro, R., Marinho, C., Silva, N., Guerra, A., et al. (2014) Comparative proteomics of an extended spectrum $\beta$-lactamase producing Escherichia coli strain from the Iberian wolf. J Proteomics 104: 80-93.

Grzywaczewski, G., Kowalczyk-Pecka, D., Cios, S., Bojar, W., Jankuszew, A., and Bojar, H. (2016) Tawny owl (Strix aluco) as a potential transmitter of Enterobacteriaceae epidemiologically relevant for forest service workers, nature protection service and ornithologists. Ann Agric Environ Med 24: 62-65.

Guenther, S., Aschenbrenner, K., Stamm, I., Bethe, A., Semmler, T., Stubbe, A., et al. (2013) Comparable high rates of extended-Spectrum-Beta-lactamase-producing Escherichia coli in birds of prey from Germany and Mongolia. PLoS One 7: e53039.

Guenther, S., Semmler, T., Stubbe, A., Stubbe, M., Wieler, L.H., and Schaufler, K. (2017) Chromosomally encoded ESBL genes in Escherichia coli of ST38 from Mongolian wild birds. I Antimicrob Chemother 72: 1310-1313.

Guiral, E., Goncalves Quiles, M., Munoz, L., MorenoMorales, J., Alejo-Cancho, I., Salvador, P., et al. (2019) Emergence of resistance to quinolones and beta-lactam antibiotics in Enteroaggregative and Enterotoxigenic Escherichia coli causing Traveler's diarrhea. Antimicrob Agents Chemother 63: e01745-01718.

Hassen, B., Abbassi, M.S., Ruiz-Ripa, L., Mama, O.M., Hassen, A., Torres, C., and Hammami, S. (2019) High prevalence of $\mathrm{mcr}-1$ encoding colistin resistance and first identification of bla $\mathrm{CTX}-\mathrm{M}-55$ in ESBL/CMY-2-producing Escherichia coli isolated from chicken faeces and retail meat in Tunisia. Int J Food Microbiol 318: 108478.

Hernandez, J., Johansson, A., Stedt, J., Bengtsson, S., Porczak, A., Granholm, S., et al. (2013) Characterization and comparison of extended-Spectrum $\beta$-lactamase (ESBL) resistance genotypes and population structure of Escherichia coli isolated from Franklin's gulls (Leucophaeus pipixcan) and humans in Chile. PLoS One 8: e76150.

Iredell, J., Brown, J., and Tagg, K. (2016) Antibiotic resistance in Enterobacteriaceae: mechanisms and clinical implications. BMJ 352: h6420. 
Kojima, Y., Harada, S., Aoki, K., Ishii, Y., Sawa, T., Hasegawa, K., et al. (2014) Spread of CTX-M-15 extended-spectrum $\beta$-lactamase-producing Escherichia coli isolates through household contact and plasmid transfer. J Clin Microbiol 52: 1783-1785.

Lee, C.-R., Lee, J., Park, K., Jeon, J., Kim, Y., Jeong, B., and Lee, S. (2018) The need for efforts to obtain high quality evidence in a one health approach. Biomed Res 29: 2355-2361.

Leite-Martins, L.R., Mahu, M.I., Costa, A.L., Mendes, A., Lopes, E., Mendonca, D.M., et al. (2014) Prevalence of antimicrobial resistance in enteric Escherichia coli from domestic pets and assessment of associated risk markers using a generalized linear mixed model. Prev Vet Med 117: 28-39.

Life Egyptian Vulture (LEV) (2019) Seguimiento De La Población De Guirres En Canarias. https://www.life gyptianvulture.it/es/sin-categorizar/seguimiento-de-lapoblacion-de-guirres-en-canarias/.

Lopez-Cerero, L., Lopez-Hernandez, I.., Blanco, G., Caballero, F.J., de Alba, P.D., and Hernandez, A.P. (2017) High prevalence of ESBL-producing $E$. coli colonization among wild vultures: comparative study between sedentary and migratory vultures. ECCMID 2017 Proceddings book, Vienna, Austria, p. P1074

Ma, Y.-X., Wang, C.-Y., Li, Y.-Y., Li, J., Wan, Q.-Q., Chen, J.-H., et al. (2020) Considerations and caveats in combating ESKAPE pathogens against nosocomial infections. Adv Sci 7: 1901872.

Marinho, C.M., Santos, T., Gonçalves, A., Poeta, P., and Igrejas, G. (2016) A decade-long commitment to antimicrobial resistance surveillance in Portugal. Front Microbiol 7: $1650-1650$.

Marques, C., Belas, A., Franco, A., Aboim, C., Gama, L.T., and Pomba, C. (2018) Increase in antimicrobial resistance and emergence of major international high-risk clonal lineages in dogs and cats with urinary tract infection: 16 year retrospective study. $J$ Antimicrob Chemother 73: 377-384.

Marques, C., Gama, L.T., Belas, A., Bergström, K., Beurlet, S., Briend-Marchal, A., et al. (2016) European multicenter study on antimicrobial resistance in bacteria isolated from companion animal urinary tract infections. $B M C$ Vet Res 12: 213.

Mora, A., Ortega, N., Garcia, E., Viso, S., Candela, M., Dahbi, G., et al. (2014) First characterization of Escherichia coli strains isolated from wildlife griffon vulture (Gyps fulvus ) in the southeast of Spain. Open J Vet Med 04: 329-333.

Moreno-Opo, R., Trujillano, A., and Margalida, A. (2020) Larger size and older age confer competitive advantage: dominance hierarchy within European vulture guild. Sci Rep 10: 2430.

Nicolas-Chanoine, M.H., Bertrand, X., and Madec, J.Y. (2014) Escherichia coli ST131, an intriguing clonal group. Clin Microbiol Rev 27: 543-574.

Oteo, J., Mencia, A., Bautista, V., Pastor, N., Lara, N., Gonzalez-Gonzalez, F., et al. (2018) Colonization with Enterobacteriaceae-producing ESBLs, AmpCs, and OXA48 in wild Avian species, Spain 2015-2016. Microb Drug Resist 24: 932-938.
Pinto, L., Radhouani, H., Coelho, C., Martins da Costa, P., Simoes, R., Brandao, R.M., et al. (2010) Genetic detection of extended-spectrum beta-lactamase-containing Escherichia coli isolates from birds of prey from Serra da Estrela natural Reserve in Portugal. Appl Environ Microbiol 76: 4118-4120.

Poeta, P., Radhouani, H., Igrejas, G., Goncalves, A., Carvalho, C., Rodrigues, J., et al. (2008) Seagulls of the Berlengas natural reserve of Portugal as carriers of fecal Escherichia coli harboring CTX-M and TEM extendedspectrum $\beta$-lactamases. Appl Environ Microbiol 74: 7439-7441.

PubMLST (2020) Escherichia coli (Achtman) MLST locus/sequence definitions database. The Department of Zoology, University of Oxford, UK. Accessed on 20/05/2020. https://pubmlst.org/bigsdb?db=pubmlst_ecoli_ achtman_seqdef.

Pulss, S., Stolle, I., Stamm, I., Leidner, U., Heydel, C., Semmler, T., et al. (2018) Multispecies and clonal dissemination of OXA-48 Carbapenemase in Enterobacteriaceae from companion animals in Germany, 2009-2016. Front Microbiol 9: 1265-1265.

Puño-Sarmiento, J., Medeiros, L., Chiconi, C., Martins, F., Pelayo, J., Rocha, S., et al. (2013) Detection of diarheagenic Escherichia coli strains isolated from dogs and cats in Brazil. Vet Microbiol 166: 676-680.

Radhouani, H., Poeta, P., Goncalves, A., Pacheco, R., Sargo, R., and Igrejas, G. (2012) Wild birds as biological indicators of environmental pollution: antimicrobial resistance patterns of Escherichia coli and enterococci isolated from common buzzards (Buteo buteo). J Med Microbiol 61: 837-843.

Robinson, T.P., Bu, D.P., Carrique-Mas, J., Fèvre, E.M., Gilbert, M., Grace, D., et al. (2016) Antibiotic resistance is the quintessential One Health issue. Trans $R$ Soc Trop Med Hyg 110: 377-380.

Rocha-Gracia, R.C., Cortes-Cortes, G., Lozano-Zarain, P., Bello, F., Martinez-Laguna, Y., and Torres, C. (2015) Faecal Escherichia coli isolates from healthy dogs harbour CTX-M-15 and CMY-2 beta-lactamases. Vet $J$ 203: 315-319.

Ruiz, E., Saenz, Y., Zarazaga, M., Rocha-Gracia, R., Martinez-Martinez, L., Arlet, G., and Torres, C. (2012) qnr, aac $\left(6^{\prime}\right)-\mathrm{lb}-\mathrm{cr}$ and qepA genes in Escherichia coli and Klebsiella spp.: genetic environments and plasmid and chromosomal location. I Antimicrob Chemother 67: 886-897.

Rumi, M., Mas, J., Elena, A., Cerdeira, L., Muñoz, M.E., Lincopan, N., et al. (2019) Co-occurrence of clinically relevant $\beta$-lactamases and $m c r-1$ encoding genes in Escherichia coli from companion animals in Argentina. Vet Microbiol 230: 228-234.

Saputra, S., Jordan, D., Mitchell, T., Wong, H.S., Abraham, R.J., Kidsley, A., et al. (2017) Antimicrobial resistance in clinical Escherichia coli isolated from companion animals in Australia. Vet Microbiol 211: 43-50.

Sato, T., Harada, K., Usui, M., Tsuyuki, Y., Shiraishi, T., Tamura, Y., and Yokota, S.I. (2018) Tigecycline susceptibility of Klebsiella pneumoniae complex and Escherichia coli isolates from companion animals: the prevalence of tigecycline-nonsusceptible $K$. pneumoniae complex, 
including internationally expanding human pathogenic lineages. Microb Drug Resist 24: 860-867.

Sevilla, E., Marín, C., Delgado-Blas, J.F., González-Zorn, B., Vega, S., Kuijper, E., et al. (2020) Wild griffon vultures (Gyps fulvus) fed at supplementary feeding stations: potential carriers of pig pathogens and pig-derived antimicrobial resistance? Transboundary Emerging Dis 67: 1295-1305.

Sharma, P., Maherchandani, S., Shringi, B.N., Kashyap, S. K., and Sundar, K.S.G. (2018) Temporal variations in patterns of Escherichia coli strain diversity and antimicrobial resistance in the migrant Egyptian vulture. Infect Ecol Epidemiol 8: 1450590.

Shnaiderman-Torban, A., Navon-Venezia, S., Dahan, R., Dor, Z., Taulescu, M., Paitan, Y., et al. (2020) CTX-M-15 producing Escherichia coli sequence type 361 and sequence type 38 causing bacteremia and umbilical infection in a neonate foal. J Equine Vet Sci 85: 102881.

Stolle, I., Prenger-Berninghoff, E., Stamm, I., Scheufen, S., Hassdenteufel, E., Guenther, S., et al. (2013) Emergence of OXA-48 carbapenemase-producing Escherichia coli and Klebsiella pneumoniae in dogs. $J$ Antimicrob Chemother 68: 2802-2808.

Suay-Garcia, B., Galan, F., Rodriguez-Iglesias, M.A., and Perez-Gracia, M.T. (2019) Detection and characterization of extended-spectrum beta-lactamases-producing Escherichia coli in animals. Vector-Borne Zoonotic Dis 19: 115-120.

Tauler-Ametler, H., Pretus, J., Hernandez-Matias, A., OrtizSantaliestra, M., Mateo, R., and Real, J. (2018) Domestic waste disposal sites secure food availability but diminish plasma antioxidants in Egyptian vulture. Sci Total Environ 650: 1382-1391.

Tuerena, I., Williams, N.J., Nuttall, T., and Pinchbeck, G. (2016) Antimicrobial-resistant Escherichia coli in hospitalised companion animals and their hospital environment. J Small Anim Pract 57: 339-347.

Ulstad, C.R., Solheim, M., Berg, S., Lindbaek, M., Dahle, U. R., and Wester, A.L. (2016) Carriage of ESBL/AmpCproducing or ciprofloxacin non-susceptible Escherichia coli and Klebsiella spp. in healthy people in Norway. Antimicrob Resist Infect Control 5: 57.

Walkty, A., Karlowsky, J.A., Adam, H.J., Lagace-Wiens, P., Baxter, M., Mulvey, M.R., et al. (2016) Frequency of $\mathrm{mcr}-$ 1-mediated colistin resistance among Escherichia coli clinical isolates obtained from patients in Canadian hospitals (CANWARD 2008-2015). CMAJ Open 4: E641-E645.

Wang, J., Ma, Z.-B., Zeng, Z.-L., Yang, X.-W., Huang, Y., and Liu, J.-H. (2017) The role of wildlife (wild birds) in the global transmission of antimicrobial resistance genes. Zool Res 38: 55-80.

WHO (2017) Global priority list of antibiotic-resistant bacteria to guide research, Discovery, and Development of New Antibiotics http://www.who.int/medicines/publications/WHOPPL-Short_Summary_25Feb-ET_NM_WHO.pdf.

Zorgani, A., Almagatef, A., Sufya, N., Bashein, A., and Tubbal, A. (2017) Detection of CTX-M-15 among uropathogenic Escherichia coli isolated from five major hospitals in Tripoli, Libya. Oman Med J 32: 322-327. 